\title{
Median Arcuate Ligament Compression on Celiac Trunk during Liver Transplantation Procedure
}

\author{
Kaleem Ullah, Shams Uddin and Abdul Wahab Dogar \\ Department of Liver Transplantation, Pir Abdul Qadir Shah Jeelani Institute of Medical Sciences, Gambat, Sindh, Pakistan
}

\begin{abstract}
Low insertion of median arcuate ligament (MAL) can cause compression over the celiac trunk with subsequent complications. During liver transplantation procedure, the graft artery is usually anastomosed with the hepatic artery of the recipient, which arises from the celiac trunk. MAL compression might reduce hepatic arterial blood flow to the graft, which can induce postoperative hepatic arterial thrombosis, causing graft failure.

Here, we report a case of liver transplant procedure, during which pulsation of hepatic artery of the recipient diminished dramatically, after ligation of gastro-duodenal artery. However, dissection and division of MAL restored excellent hepatic arterial blood flow. This case highlights the significance of prompt diagnosis and management of MAL compression syndrome in liver transplant recipients during transplant surgery.
\end{abstract}

Key Words: Celiac trunk, Median arcuate ligament, Liver transplant.

How to cite this article: Ullah K, Uddin S, Dogar AW. Median Arcuate Ligament Compression on Celiac Trunk during Liver Transplantation Procedure. J Coll Physicians Surg Pak 2022; 32(02):250-252.

\section{INTRODUCTION}

Median arcuate ligament (MAL) connects both the diaphragmatic crurae to the celiac trunk. The celiac trunk is predisposed to compression by MAL, with high origin of celiac trunk or low insertion of MAL. Symptoms produced, due to compression of MAL on celiac trunk, are referred to as median arcuate ligament syndrome (MALS). Dissection and division of this ligament, or sometimes arterial reconstruction, is needed to enhance arterial blood flow in celiac trunk in patients, who complain of intermittent or postprandial abdominal pain. ${ }^{1}$

During liver transplantation procedure, the graft artery is anastomosed with the hepatic artery of the recipient, which arises from the celiac trunk. Sometimes the gastro-duodenal artery is ligated for getting the length of hepatic artery. Some authors suggest that MAL compression reduces mean hepatic arterial blood flow velocity. ${ }^{2}$ This decreased blood supply can induce hepatic arterial thrombosis, causing graft failure. This condition is considered as a major risk factor for recipient's hepatic arterial thrombosis. $^{3}$

Correspondence to: Dr. Kaleem Ullah, Department of Liver Transplantation, Pir Abdul Qadir Shah Jeelani Institute of Medical Sciences, Gambat, Sindh, Pakistan E-mail: drkaleempk@hotmail.com

Received: May 06, 2020; Revised: July 19, 2020;

Accepted: July 19, 2020

DOI: https://doi.org/10.29271/jcpsp.2022.02.250
Here, we present a case of liver transplant procedure, during which pulsation of hepatic artery of the recipient diminished dramatically, after ligation of gastro-duodenal artery. However, dissection and division of MAL restored excellent hepatic arterial blood flow to the graft.

\section{CASE REPORT}

A 50-year male, who presented with decompensated chronic liver disease and hepatocellular carcinoma in the background of hepatitisC-related cirrhosis. His pastmedical history wassignificant for epilepsy. His child-pugh score was 7 (A). He was planned for a living donor liver transplant procedure. His pre-transplant abdominal computed tomography scan demonstrated "hook sign" and narrowing of the celiac trunk secondary to compression by MAL, which were missed initially (Figure 1). During porta hapatis dissection, recipient's hepatic artery was found to have normal flow, but when gastro-duodenal artery was ligated, pulsation of hepatic artery dramatically reduced. After reviewing his scan, skeletonisation of celiac artery was done till the origin from the aorta and by releasing the MAL, a convincing pulsation of hepatic artery was gained. Then, anastomosis (end-to-end) between recipient's hepatic artery proper and donor's right hepatic artery was done (Figure 2). Normal blood flow in the graft artery was confirmed by intraoperative Doppler ultrasound. Postoperative recovery was uneventful and the patient was sent home on $11^{\text {th }}$ postoperative day having normal liver function tests. At four weeks follow-up, the Dopplerultrasound arterial flow was within normal limits.

\section{DISCUSSION}

A clinical syndrome of postprandial abdominal pain related to celiac trunk compression by MAL was first described by Dunbar et al. in $1965 .{ }^{4}$ The celiac trunk narrowing related to compres- 
sion by MAL was angiographically demonstrated to a variable degree in $10 \%$ to $50 \%$ of patients in another study. Jurim et al. in their series found celiac trunk compression by MAL in $10 \%$ of patients undergoing livertransplantation. ${ }^{2}$

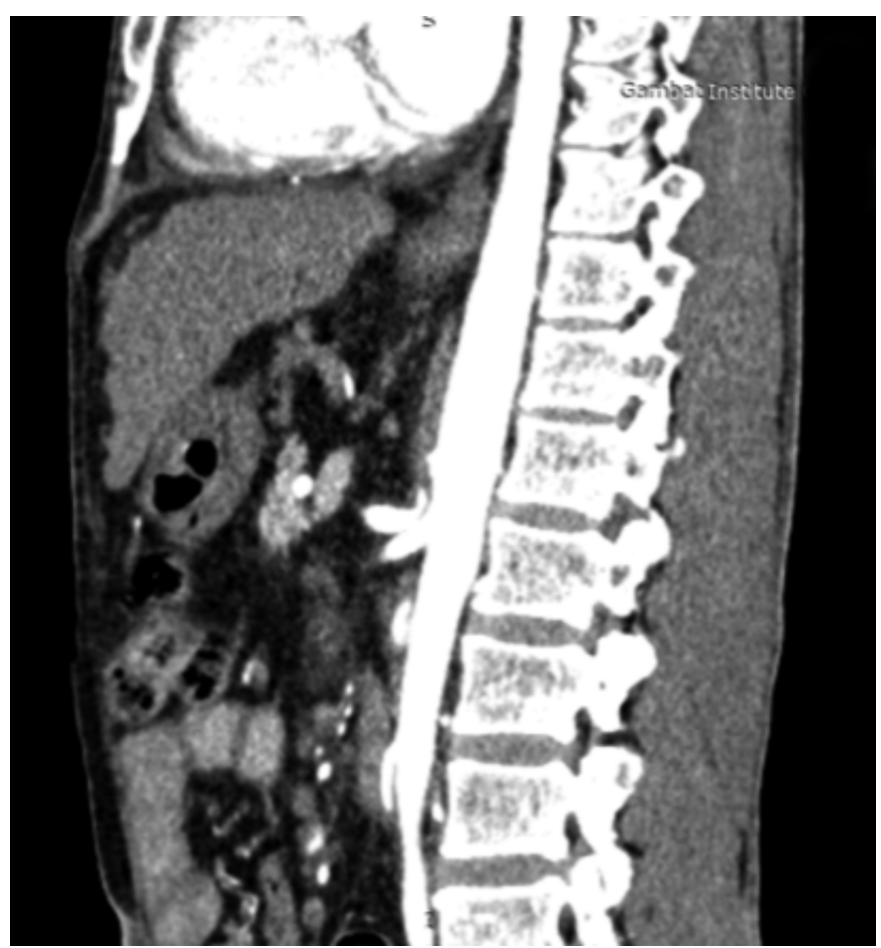

Figure 1: CTscanabdomen. Arrow points towards “hooksign".

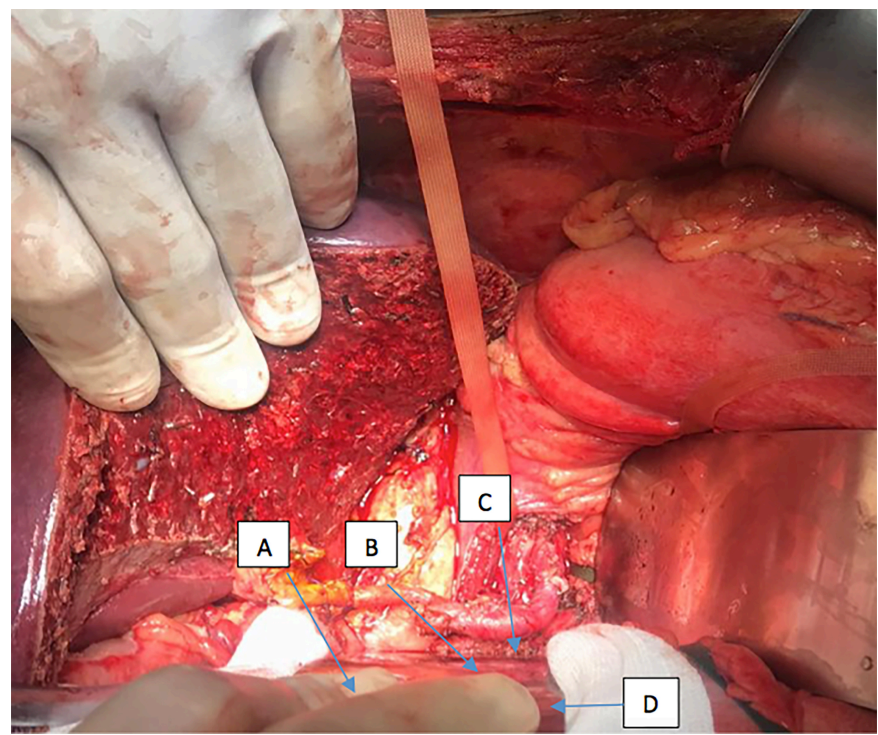

Figure 2: Operative findings. Arrow A (site of hepatic artery anastomosis), Arrow B (released arcuate ligament), Arrow C (aorta), Arrow D (celiac trunk).

Reuter studied the accentuation of compression on celiac trunk during deep expiration as well as augmentation of the blood flow through the retrograde collaterals from pancreatico-duodenal system of superior mesenteric artery, which compensates for the compressed celiac trunk flow. ${ }^{6}$ As MAL is inserted into diaphragmatic crurae, its position during respiratory cycle and resulting compression on celiac trunk vary with respiration. ${ }^{7}$
Computed tomographic angiography (CTA) is considered to be less invasive diagnostic modality than angiography for diagnosis of this condition. On sagittal plane reconstructed images, there appears a relatively specific "hook sign" due to narrowing of the celiac trunk by MAL. This characteristic sign is very useful to differentiate celiac trunk narrowing related to MAL compression from various other diseases of celiactrunknarrowing, such as atherosclerosis. Additional findings include thickening of the MAL of more than $4 \mathrm{~mm}$ and post-stenotic dilatation. ${ }^{8,9}$

Nevertheless, in liver transplant surgery, during dissection of porta hepatis, the gastro-duodenal artery; is sometimes ligated for getting length of the hepatic artery, disrupting the collateral supply, making graft's arterial supply totally dependent on celiac trunk. It is critical to diagnose MALS to avoid risk of hepatic arterial thrombosis, secondary to decreased blood supply and subsequent graft failure. ${ }^{10}$ In liver transplant recipients, it is mandatory to study pre-transplant CTA imaging studies to rule out this condition.

This case highlights the significance of prompt diagnosis and management of MALS in a recipient during liver transplant surgery. Care should be taken before ligation of gastro-duodenal artery and distal pulsation in hepatic artery should be checked after clamping gastro-duodenal artery for preservation of this alternate blood supply.

\section{PATIENT'S CONSENT:}

Informed consent was obtained from the patient to publish the data concerning this case.

\section{CONFLICT OF INTEREST:}

The authors declared no conflict of interest.

\section{AUTHORS' CONTRIBUTION:}

KU: Wrote the paper and assisted the consultant in the procedure.

SU: Performed the procedure and participated in data collection. AWD: Supervised the wholeteam.

\section{REFERENCES}

1. Kim EN, Lamb K, Relles D, Moudgill N, DiMuzio PJ, Eisenberg JA. Median arcuate ligament syndrome-review of this rare disease. JAMA Surg 2016; 151(5):471-7. doi:10.1001/ jamasurg.2016.0002.

2. Jurim O, Shaked A, Kiai K, Millis JM, Colquhoun SD, Busuttil RW. Celiac compression syndrome and liver transplantation. Ann Surg 1993; 218(1):10. doi: 10.1097/ 00000658-199307000-00003.

3. Jiang ZJ, Liang TB, Feng XN, Wang WL, Shen $Y$, Zhang $M$, et al. Arcuate ligament syndrome inducing hepatic artery thrombosis after liver transplantation. Hepatobiliary Pancreat Dis Int 2008; 7(4):433-6. http://europepmc.org/ article/med/18693183.

4. Dunbar JD, Molnar W, Beman FF, Marable SA. Compression of the celiac trunk and abdominal angina: Preliminary report of 15 cases. Am J Roentgenol 1965; 95(3):731-44. doi/pdf/10.2214/ajr.95.3.731.

5. Lindner $\mathrm{HH}$, Kemprud E. A clinic anatomical study of the 
actuate ligament of the diaphragm. Arch Surgery 1971; 103(5):600-5. doi:10.1001/archsurg.1971.0135011010 2016.

6. Reuter SR. Accentuation of celiac compression by the median actuate ligament of the diaphragm during deep expiration. Radiology 1971; 98(3):561-4. doi.org/10. 1148/98.3.561.

7. Reuter SR, Bernstein EF. The anatomic basis for respiratory variation in median arcuate ligament compression of the celiac artery. Surgery 1973; 73(3):381-5. doi.org/10.5555/ uri:pii:003960607390305X.

8. Horton KM, Talamini MA, Fishman EK. Median arcuate ligament syndrome: evaluation with CT angiography. Radiographics 2005; 25(5):1177-82. doi.org/10.1148/ rg. 255055001.

9. Fong JK, Poh AC, Tan AG, Taneja R. Imaging findings and clinical features of abdominal vascular compression syndromes. Am J Roentgenol 2014; 203(1):29-36. doi/full/ 10.2214/AJR.13.11598.

10. Lubrano J, Scatton O, Randone B, Molinier N, Massault PP, Legmann $\mathrm{P}$, et al. Median arcuate ligament in orthotopic liver transplantation: Relevance to arterial reconstruction. Transplant Proc 2008; 40(10):pp.3532-5. doi.org/10.1016/j. transproceed.2008.07.133. 